\title{
VOLATILITY AND RISK OF EQUITY IN RETIREMENT PORTFOLIOS
}

\author{
Paul Snyman* \\ University of Johannesburg \\ pauls@uj.ac.za
}

Received: June 2015

\author{
Nico Smith" \\ University of Johannesburg \\ nsmith@uj.ac.za
}

Accepted: September 2015

\begin{abstract}
Financial planners often manage volatility believing that it is the same as managing risk. The FTSE/JSE Top 40 Index (Topi) and the FTSE/JSE All Share Index (Alsi) were used as samples to investigate volatility and risk in equity investments. A target return was determined as a benchmark for required return. The volatility analysis indicated that investments in the Topi and the Alsi were too risky for a retirement portfolio. Five sets of actual investments in the Topi and Alsi were then simulated. The internal rate of return (IRR) of each investment was determined and compared with the target return. This revealed that the risk of each of the five simulated sets of investments was acceptable for a retirement portfolio. It was concluded that volatility analysis of monthly returns was not suitable to determine the risk of equity investments in retirement portfolios.
\end{abstract}

Keywords

Retirement portfolio, equity, volatility, risk, investment risk

*Mr P Snyman is a senior lecturer in the Department of Finance and Investment Management, University of Johannesburg, South Africa.

\#Prof N Smith is professor in the Department of Finance and Investment Management, University of Johannesburg, South Africa. 


\section{INTRODUCTION}

It is a worldwide problem that only a very small percentage of the population retires with sufficient capital to maintain their standard of living after retirement. In South Africa only about $6 \%$ of retired people are financially independent and maintain an acceptable standard of living after retirement (Strydom, 2007:3).

The low number of financially independent retirements may be attributed to the limited equity content of retirement portfolios. This problem is exacerbated by Regulation 28 of the Pensions Fund Act 24 of 1956, which stipulates that a maximum of $75 \%$ of an individual retirement fund may be invested by retirement institutions in equities RSA (1956).

The underutilisation of equities persists, notwithstanding the findings of various researchers that equity is the best-performing asset over the long term (Rayhorn \& Janson, 2011:8; Hickman, Hunter, Byrd, Beck, \& Terpening, 2001; Butler \& Domian, 1993; Butler 1991; Reichenstein 1986; and Levy 1978). Nonetheless, retirement fund managers continue to limit equity in retirement portfolios because equity is perceived as a risky investment.

Pension funds often recommend that members reduce the volatility of their fund as they move towards pension age and beyond. The pension fund of the University of Johannesburg (UJ) advises its members to move into funds with less equity and more bond exposure from the age of 48 , in order to reduce volatility. They conclude that market-linked portfolios are not suitable for the 3 5 final years of a member's membership of the fund (University of Johannesburg Pension Fund, 2008:3). The Durban Pension Fund lists volatility of returns as a risk to be considered, and proposes investing in cash and short-dated fixed interest securities as one of its strategies to minimise volatility risk (Durban Pension Fund, n.d.:5).

Pension funds employ bonds and cash to meet their liabilities, specifically to fund members who are retired. This excludes the option to utilise equities for this purpose.

Risk is measured as volatility of the returns of investments (Markowitz, 1952). However, volatility measures used to express risk in retirement portfolios are problematic since they are based on short-term returns, whereas investments in retirement portfolios are normally long term. It is therefore questionable whether risk measurements of an equity investment based on short-term data are suitable for evaluating the risk of a long-term investment. The link between volatility and risk results in portfolio managers and financial planners managing volatility, believing that this is the same as managing risk.

In the following section the goal of this study is presented and the existing literature on risk measurement is considered. The research methodology is then outlined, followed by the data analysis and interpretation. The article concludes with recommendations on how equity risk should be treated in a retirement portfolio.

The goal of this research project was to determine whether volatility measures, and specifically the standard deviation (STD) of returns of the FTSE/JSE Top 40 Index (Topi) and the FTSE/JSE All Share Index (Alsi), would give an appropriate indication of the risk of including investments in the Topi and Alsi in a retirement portfolio.

The volatility was investigated by determining the volatility measurements of the Topi and the Alsi. These volatility numbers were then used to determine the estimated probability of not reaching a target return. This was compared to the probability of actual investments in the Topi and Alsi not reaching a target return. 


\section{RETIREMENT RISK}

In a retirement portfolio risk needs to be determined in the accumulation of the investment phase and the retirement phase, when the accumulated capital must be utilised to generate retirement income. How investors address these risk phases will have a significant impact on the level of income that will be available to them during retirement (De Swardt, 2001).

\subsection{Lifecycle risk}

The risk levels that individuals can tolerate depend to a large extent on their age. The younger the individual, the more time there is to recover from adverse markets or losses.

According to Malkiel (2007), risk tolerance depends on two factors: an appetite for risk and risk capacity. Appetite for risk is subject to an individual's personal inclinations, whilst capacity for risk depends on an individual's position in the retirement lifecycle (Hickman et al., 2001).

Financial advisors tend to follow the lifecycle investment recommendation and move retirement funds towards less risky investments with lower volatility such as bonds or treasury bills as members approach retirement This is sometimes done years before retirement is due (Hickman et al., 2001).

Malkiel (2007) proposes that retirement investment portfolios should consist of varying proportions of equity, bonds, property and cash, depending on a person's position in the lifecycle. These proposals are summarised in TABLE 1 .

TABLE 1: Investment composition based on life cycle position

\begin{tabular}{lcccc}
\hline & Equities & Property & Bonds & Cash \\
\hline Mid-20s & $65 \%$ & $10 \%$ & $20 \%$ & $5 \%$ \\
Late 30s - early 40s & $60 \%$ & $10 \%$ & $25 \%$ & $5 \%$ \\
Mid-50s & $50 \%$ & $12.5 \%$ & $32.5 \%$ & $5 \%$ \\
Late 60s & $35 \%$ & $15 \%$ & $40 \%$ & $10 \%$ \\
\hline
\end{tabular}

Source: Malkiel, 2007:346-347

TABLE 1 indicates relatively low equity content from the outset of a person's retirement preparation lifecycle. The portfolios presented in TABLE 1 are compiled on a perceptual risk return basis (Malkiel, 2007).

De Villiers-Strijdom (2013) compares a living annuity with $75 \%$ equity and $25 \%$ bonds with other funds consisting of less equity and more bond exposure as well as life annuities. According to De Villiers-Strijdom:

- Retirees with all their capital invested in life annuities would be worse off than in any of the permutations of living annuities with a combination between equities and bonds; and

- The living annuities with the highest equity content outperform $80 \%$ of other options $80 \%$ of the time (De Villiers-Strijdom, 2013). 
The equity content of the portfolios investigated by De Villiers-Strijdom (2013) had significantly higher equity content than those presented in TABLE 1 . It would therefore appear that risk should be investigated in greater depth before a retirement portfolio is constructed.

\subsection{Variance and standard deviation}

Variance and STD measure the degree of dispersion from the mean of the returns of an investment (Botha at al., 2014; Brown \& Reilly, 2009). The terms volatility, variance and STD are used interchangeably to describe volatility. In this study, STD is used to evaluate volatility. As early as 1952, Markowitz specified the risk of a portfolio as the STD of actual returns from the mean return (Markowitz, 1952).

To apply STD to assess risk, the data (in this case investment returns) needs to be normally distributed. However, the investment returns of equity investments are not necessarily normally distributed (Nawrocki, 1999).

A further drawback of using STD to express risk is that upside volatility is irrelevant when measuring risk, since it does not increase risk should there be a greater probability of achieving a higher return than anticipated (Nawrocki, 1999).

In addition, STD measures both the upside and downside volatility of the return on investment. This volatility can distort the actual risk figure. If the distribution of the data is also skewed, the indicated risk figure may become meaningless.

\subsection{Intrinsic value and volatility}

Intrinsic value is the value of an asset based on the present value of cash flows or the income it will yield in the future (Jordan \& Miller, 2008). Volatility can be defined as movements of returns from expected returns which cause equity market prices to deviate from intrinsic value.

Over the long term, equity market prices tend to revert to intrinsic value. Short-term variations in share prices are therefore not always a true reflection of the risk of investing in a share (Shiller, 1998).

\section{RESEARCH METHODOLOGY}

This study followed a quantitative explorative approach to determine the appropriateness of existing risk measurement techniques to quantify the risk of equity investments in retirement portfolios.

Risk measures that are used to quantify risk in retirement portfolios include:

- Variance and standard deviation (Brown \& Reilly, 2009);

- Beta (Brown \& Reilly, 2009);

- Semi-variance and semi-standard deviation (Nawrocki, 1999);

- The Sharpe ratio (Jordan \& Miller, 2008);

- The Sortino ratio (Rollinger \& Hoffman, 2013); and

- The Treynor ratio (Brown \& Reilly, 2009). 
The aim of this study was to determine whether the analysis of the volatility of returns presents an accurate proxy for investment risk. The study did not, however, extend to evaluating the different methodologies of analysing risk.

The study analysed whether monthly returns or IRR over a period should be applied as input to determine risk in equity investments. A target return was determined as a benchmark for returns of investments in the Topi and Alsi.

The probability of returns of investments in the Topi and Alsi not reaching the target return was then evaluated. Indices as opposed to actual investments were used to eliminate the bias a fund manager would add to the returns and volatility. Indices also provided a diversified portfolio of equities. The reason equity only indices were used was to isolate the risk added by equity investments.

The volatility of monthly returns of the Topi and the Alsi was determined using descriptive statistics of the monthly returns over the study period. These volatility results were used to evaluate the risk of investments in the Topi and Alsi.

Five sets of actual investments (Set A to Set $\varepsilon$ ) were then simulated by taking the actual returns realised in the Topi and Alsi as the return for the simulated investments over the study period. The internal rate of return (IRR) of all these investments was established. The volatility of these IRRs was then determined by means of descriptive statistics. The volatility of the IRRs of the five sets of simulated investments was then compared to the volatility of the monthly returns of the Topi and the Alsi.

\subsection{Population and sample selection}

The population of this study consisted of general equity index investments that a retirement portfolio could invest in on the JSE Ltd. The Topi and Alsi equity indices were selected as samples, as they represent the top 40 shares by market capitalisation and all the listed shares on the main bourse of the JSE Ltd.

\subsection{Data collection}

The monthly closing prices, monthly dividend yields and monthly closing values of the total return index of the Topi were obtained from McGregor BFA (Anon, 2014). The Topi data ranged from 30 June 1995 to 28 February 2014. It provided 225 data points.

The monthly closing prices and dividend yields for the Alsi were also obtained from McGregor BFA. The data was in the form of a monthly index from 31 January 1960 to 28 February 2014. It provided 649 data points.

\section{DATA ANALYSIS}

The data was analysed by determining a target return, followed by an analysis of the volatility of the monthly returns of the Topi and the Alsi. Five sets of simulated investments were then generated. The IRRs of investments in the five sets of simulated investments were determined and analysed. 


\subsection{Determining the target return}

The target return is based on the minimum return required for an investment to generate a sufficient income stream to support retirees for the rest of their lives, should they retire at the age of 65 and live to the age of 100 . The target return is influenced by the retirement age, life expectancy and withdrawal rate of an individual.

The life expectancy of a female aged 65 is 82 years (Botha et al., 2014). To be conservative, a life expectancy of 100 was used to determine the target return. For the purpose of this study, the withdrawal rate of a living annuity of a female aged 65 was used and rounded down to $6.0 \%$ to determine the target return (LOA, 2008). It was decided to apply an escalation rate equal to the upper inflation range of $6 \%$ per annum targeted by the South African Reserve Bank (South African Reserve Bank, 2009).

Based on the above criteria, the target rate of return for a capital amount invested to last for 35 years ( 65 with a life expectancy of 100 ) was determined as $11.07 \%$ per annum.

\subsection{Volatility of the Topi and Alsi}

The volatility of the Topi and Alsi was determined by the STD of the monthly returns. The returns of the Topi and Alsi consisted of a change in price plus a dividend.

For the Alsi, a total return index was not available and had to be determined. It was assumed that a dividend equal to a twelfth of the dividend yield times the closing price for a month was paid every month. The dividend was then added to the accumulated index price to determine the total return index (De Villiers-Strijdom, 2013:42).

The process of determining the volatility of the Topi and the Alsi is illustrated in FIGURE 1.

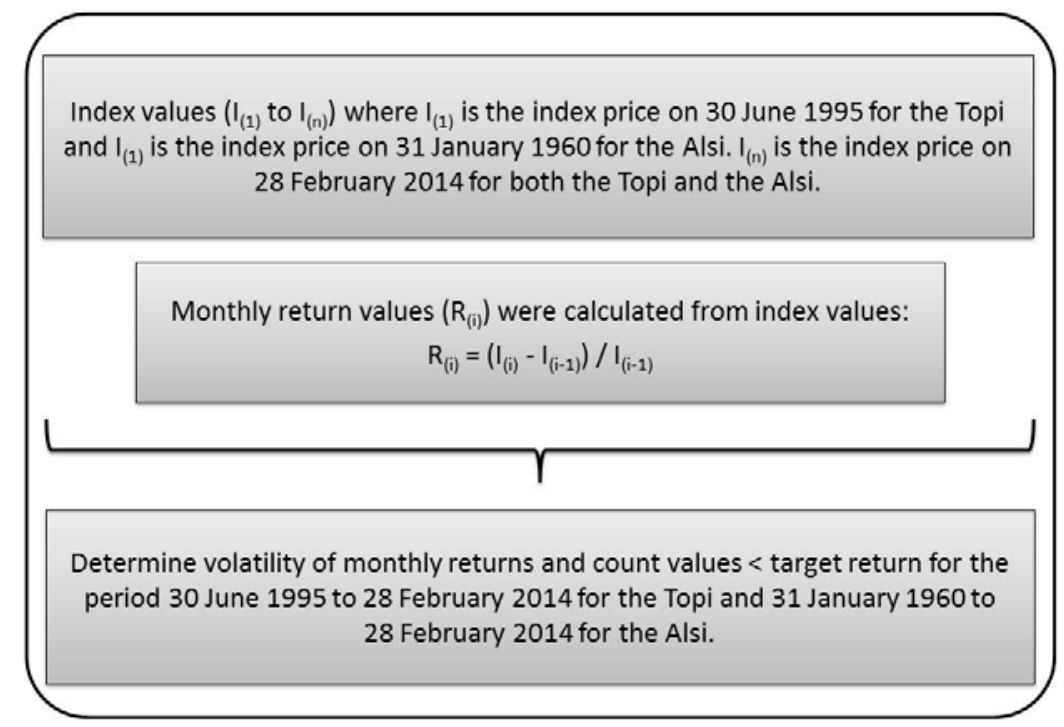

FIGURE 1: Determining the volatility of the Topi and the Alsi

Source: Authors' deductions 
FIGURE 1 illustrates the process of determining the volatility of the Topi and the Alsi. Returns less than the target return were counted as giving an indication of quantum of inadequate returns.

\subsubsection{Volatility of the Topi}

TABLE 2 presents the volatility analysis of the monthly returns of the Topi.

TABLE 2: Volatility analysis of the monthly returns of the Topi

\begin{tabular}{ll}
\hline Average return: & $1.40 \%$. \\
\hline Standard deviation: & $5.89 \%$ \\
Kurtosis: & 2.50 \\
Skewness: & -0.60 \\
Number of data points: & 225 \\
Returns < 11.07\% p.a. (target return) & 103 \\
\hline
\end{tabular}

Source: Authors' deductions

To determine acceptable risk, the probability of not achieving the target return was investigated. This study is based on a $95 \%$ confidence level, which is typically accepted as accurate enough to determine acceptable risk (Bryman \& Bell, 2003:252). A confidence interval of $95 \%$ presents 1.96 STDs (Lind, Marchal \& Wathen, 2005:285). The probability estimate of a return falling outside this confidence interval is $5 \%(100-95)$.

Downside probabilities of returns were used to evaluate the risk of an investment in the Topi. The downside probability that a return will be 1.96 STDs less than the average return is therefore $2.5 \%$ $(5 \% / 2)$. The expected return should therefore not fall below the $2.5 \%$ probability level for the risk to be acceptable.

TABLE 2 indicates that the average monthly return of the Topi is $1.40 \%$ or $16.80 \%$ per annum. The monthly STD of the Topi is $5.89 \%$ according to TABLE 2. This is equal to an annual STD of $20.40 \%$.

The average annual return of the Topi (16.80\%) minus 1.96 STDs (39.98\%) therefore provides an expected downside return of minus $23.18 \%$. This must be compared with the target return of $11.07 \%$ to assess the risk of investing in the Topi. The downside return at a $2.5 \%$ probability level should give a target return of at least $11.07 \%$ for the investment risk to be acceptable. However, the return at $2.5 \%$ is minus $23.18 \%$. This indicates a considerable risk of the target return not being obtained. TABLE 2 also indicates that $45.8 \%$ of the monthly returns fell below the target return of $11.07 \%$.

Based on this conventional analysis, it can be concluded that the risk of investing in the Topi is too high for a retirement portfolio.

\subsubsection{Volatility of the Alsi}

The results of the volatility analysis of the Alsi are presented in TABLE 3 . 
TABLE 3: Volatility analysis of the Alsi

\begin{tabular}{ll}
\hline Average return: & $1.52 \%$, equivalent to $18.24 \%$ p.a. \\
Standard deviation: & $6.05 \%$, equivalent to $20.96 \%$ annualised \\
Kurtosis: & 1.49 \\
Skewness: & -0.47 \\
Number of data points: & 649 \\
Returns < $11.07 \%$ p.a. (target return) & 284 \\
\hline
\end{tabular}

Source: Authors' deductions

TABLE 3 indicates that the average monthly return of the Alsi is $1.52 \%$ or $18.24 \%$ per annum. Thus the monthly STD of the Alsi is $6.05 \%$. This is equal to an annual STD of $20.96 \%$.

The downside return at a $2.5 \%$ probability level should give a target return of at least $11.07 \%$ for the investment risk to be acceptable. However, the return at $2.5 \%$ is minus $22.84 \%$. This indicates a considerable risk of the target return not being obtained. It was also noted that $43.8 \%$ of the monthly returns fell below the target return of $11.07 \%$.

The volatility analyses of the Topi and Alsi indicate that the probability of not achieving the required rate of return is very high. It can therefore be inferred that financial planners would be unlikely to recommend investment in the Topi or the Alsi for retirement portfolios.

\subsection{Simulated investments}

Five sets of actual investments in the Topi and Alsi were simulated. These simulations were conducted to determine the validity of the volatility of monthly returns as an indicator of risk. The volatility of the IRR of each investment was determined and compared with the target return.

FIGURE 2 illustrates how the volatility of the five sets of simulated investments was determined. It indicates the process of determining the volatility of the IRR values of the simulated investments in Set A. Set A consists of $n$ investments, with each investment consisting of a series of monthly investments that escalate annually at inflation.

Investments Al to An are created by advancing the commencement date one month at a time until the investment term reaches ten years. The maturity date of the investments is 28 February 2014.

The IRR of each investment was then determined and plotted on the commencement date of the investment. This provided a set of IRR values, the volatility of which was then determined.

The same procedure outlined in FIGURE 2 was followed for investments of Set $B$ and Set $C$, except that the term of investments for Set B was limited to 30 years and for Set $C$ to 20 years. It was considered representative that members of a retirement fund would typically be members for a term of 20 to 30 years. It was also a long enough period to allow for the market cycle to go through both extraordinary high and low points. 


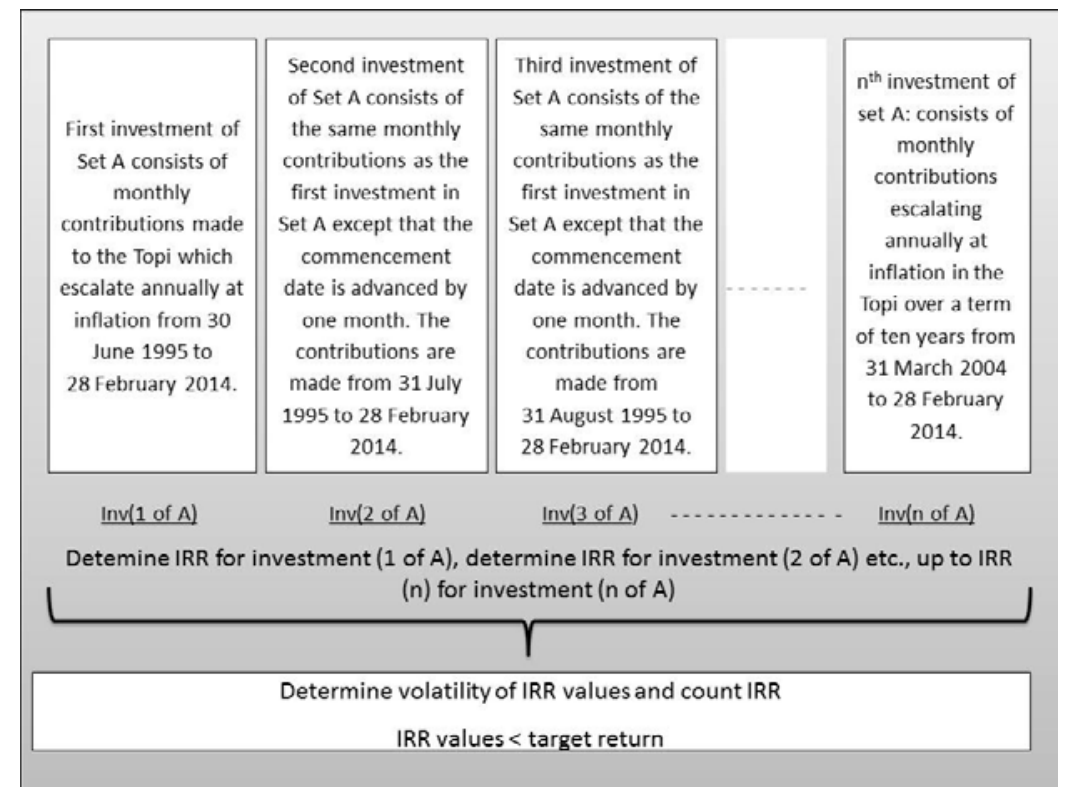

FIGURE 2: Example of the volatility analysis of simulated investments of Set A

\section{Source: Authors' deductions}

For Sets $D$ and $\varepsilon$, the investments consisted of an initial lump sum on the commencement date. Monthly income from this lump sum was withdrawn at $0.5 \%$ (6\%/12) per month (LOA, 2008:21.2) of the capital invested. In subsequent years, the withdrawal amount was escalated by $6 \%$ per year (South African Reserve Bank, 2009:1).

\subsubsection{Simulated investments in the Topi}

The first set of simulated investments investigated was Set A. This consisted of a sample of investments representing all possible monthly investments in the Topi with a minimum investment term of 10 years.

The IRR results of the Set A investments in the Topi are presented in FIGURE 3. Note that the IRR is plotted against the commencement date of the investments, which are one month apart. The IRR is determined for each investment on the maturity date of 28 February 2014.

FIGURE 3 shows the IRR values of the investments in Set $A$, which are plotted on the commencement date of the investment. For example, the IRR generated by an investment with the commencement date of 31 December 1996 is $15.8 \%$ (indicated by the red lines in FIGURE 3).

FIGURE 3 indicates that the IRR values of Set $A$ investments fall within a narrow range, between $15.5 \%$ and $16.3 \%$ per annum. All the IRRs generated by the actual investments in the Topi are well in excess of the required target return of $11.07 \%$. 


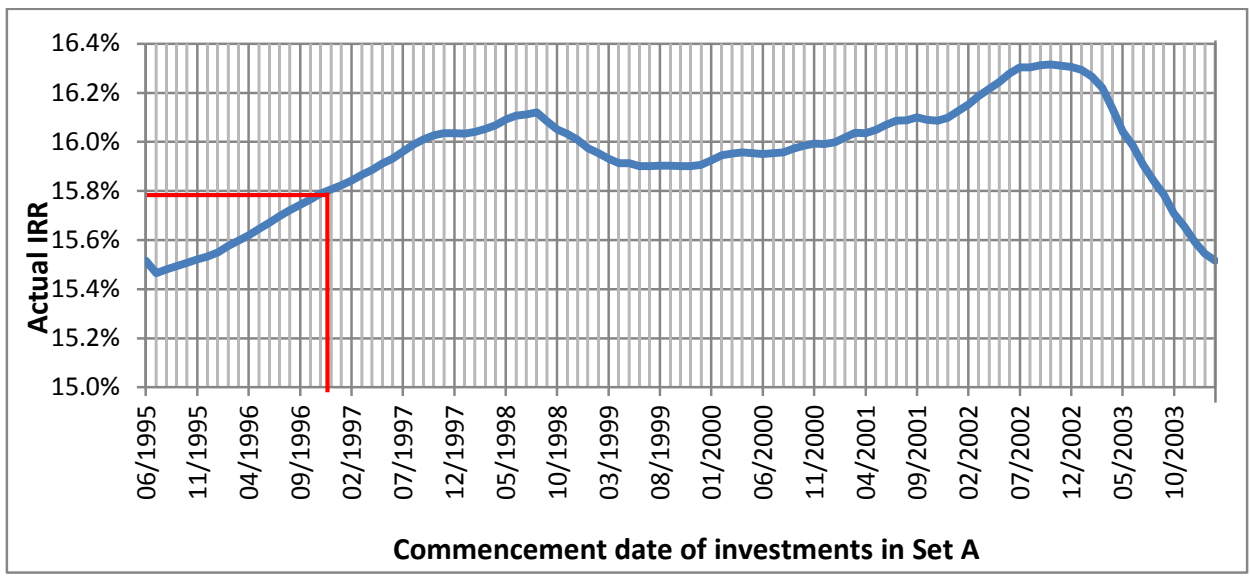

FIGURE 3: IRRs generated by the investments of Set A

Source: Authors' deductions

TABLE 4 shows the volatility of the IRRs of the investments of Set $A$.

\section{TABLE 4: Volatility of the IRRs of the investments of Set A}

\begin{tabular}{ll}
\hline Average IRR: & $15.94 \%$ p.a. \\
\hline Standard deviation: & $0.22 \%$ \\
Kurtosis: & -0.30 \\
Skewness: & -0.46 \\
Number of data points: & 105 \\
IRR< $11.07 \%$ p.a. (target return) & 0 \\
\hline
\end{tabular}

Source: Authors' deductions

TABLE 4 indicates that the STD of the IRRs of the investments in Set $A$ is $0.22 \%$. This is significantly lower than the STD of the Topi at $20.4 \%$, calculated previously from TABLE 3 .

The downside risk to invest in the Topi is indicated in TABLE 5 .

TABLE 5: Probabilities of downside IRR of the investments in Set A

\begin{tabular}{ll}
\hline Probability estimate & IRR to be less than percentage below: \\
\hline $2.5 \%$ & $15.51 \%$ p.a. \\
$0 \%$ & $11.07 \%$ p.a. (target return) \\
\hline
\end{tabular}

Source: Authors' deductions

TABLE 5 indicates an estimated probability of $2.5 \%$ that an IRR will be less than $15.51 \%$. There is no indication that the IRR will be lower than the target return of $11.07 \%$. Based on the results of the investments in Set A, the risk of investing in the Topi is acceptable for a retirement portfolio. 
It can thus be concluded that the analysis of the short-term volatility of the Topi does not provide an accurate indication of the risk of investing in the Topi over a long term in a retirement portfolio.

\subsubsection{Simulated investments in the Alsi}

Investments were also simulated in the Alsi because data was available over a longer term than that of the Topi and it represented a more inclusive population of shares to evaluate risk.

Two sets of investments were simulated in the Alsi, Set B and Set C. The commencement date of the first investment in both sets was 30 January 1960. The terms of the investments were limited to a maximum of 30 years (Set B) and 20 years (Set C).

a) Investments in Set B with a 30-year maximum investment period

The investments of Set B were considered to determine the volatility of the IRRs to assess the risk of this investment set. The results of the IRR values of investments in Set B with a maximum investment period of 30 years are presented in FIGURE 4. It should be noted that the commencement dates of the investments are one month apart and the IRR is determined for each investment on the maturity date of 30 years.

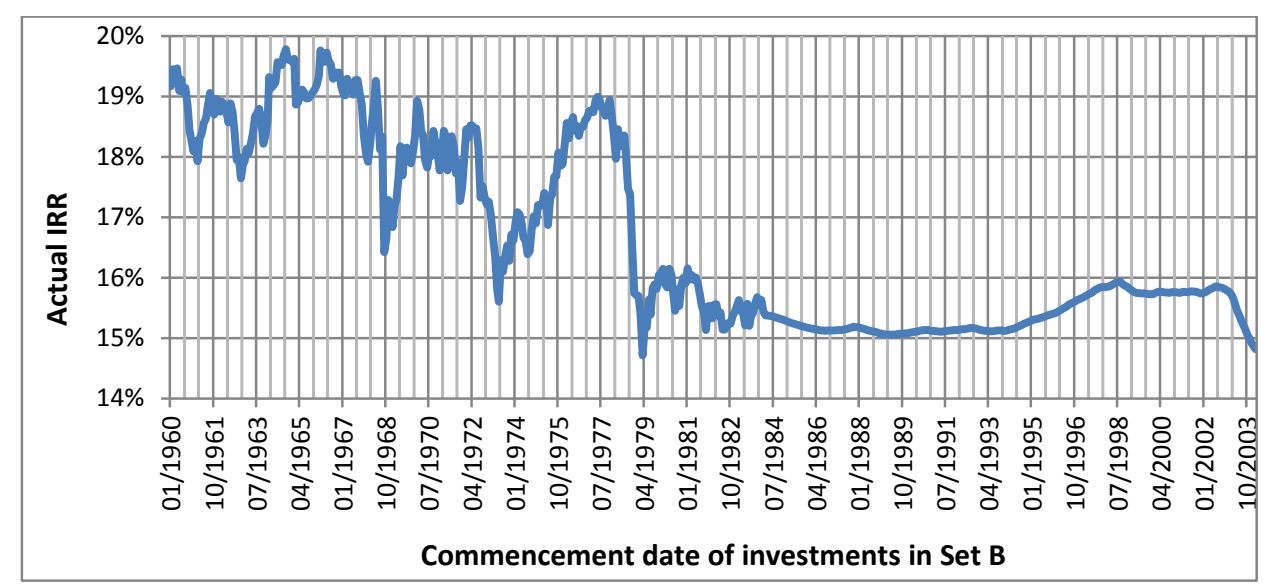

\section{FIGURE 4: IRRs generated by the monthly investments of Set B}

Source: Authors' deductions

FIGURE 4 indicates that the IRRs of the simulated investments of Set B varied between $14.7 \%$ and $19.8 \%$ per annum. The lowest recorded IRR is therefore well in excess of the target return of $11.07 \%$.

The volatility of the IRR values of the investments of Set $B$ is presented in TABLE 6 . 
TABLE 6: Volatility of the IRRs of the investments of Set B

\begin{tabular}{ll}
\hline Average IRR: & $16.64 \%$ p.a. \\
Standard deviation: & $1.54 \%$ \\
Kurtosis: & -1.29 \\
Skewness: & 0.57 \\
IRR< $11.07 \%$ p.a. (target return) & 0 \\
\hline
\end{tabular}

Source: Authors' deductions

TABLE 6 indicates that the STD of the IRRs of the investments in Set B is $1.54 \%$. This is significantly lower than the STD of the Alsi at $20.96 \%$ calculated previously from TABLE 3 .

The downside risk of investing in the Alsi is indicated in TABLE 7.

TABLE 7: Probabilities of downside IRR of the investments in Set B

\begin{tabular}{ll}
\hline Probability estimate & IRR to be less than figure below: \\
\hline $2.5 \%$ & $13.62 \%$ p.a. \\
$0 \%$ & $11.07 \%$ p.a. (target return) \\
\hline
\end{tabular}

Source: Authors' deductions

TABLE 7 indicates an estimated probability of $2.5 \%$ that the IRR will be less than $13.62 \%$. There is no indication that the IRR will be lower than the target return of $11.07 \%$. Based on these results of the investments in Set $A$, the risk of investing in the Alsi is acceptable for a retirement portfolio.

It can be concluded that the analysis of short-term volatility of the Alsi does not give an accurate indication of the risk of investing in the Alsi over a long term in a retirement portfolio.

\section{b) Set $C$ investments with a 20 year maximum investment period}

The investments of $\operatorname{Set} C$ were considered next to determine the volatility of the IRRs.

FIGURE 5 shows the results of the IRR values of investments with a maximum investment period of 20 years. It indicates that the IRRs of the simulated investments of Set $C$ varied between $11.5 \%$ and $23.6 \%$ per annum. The lowest recorded IRR was still in excess of the target return of $11.07 \%$. 


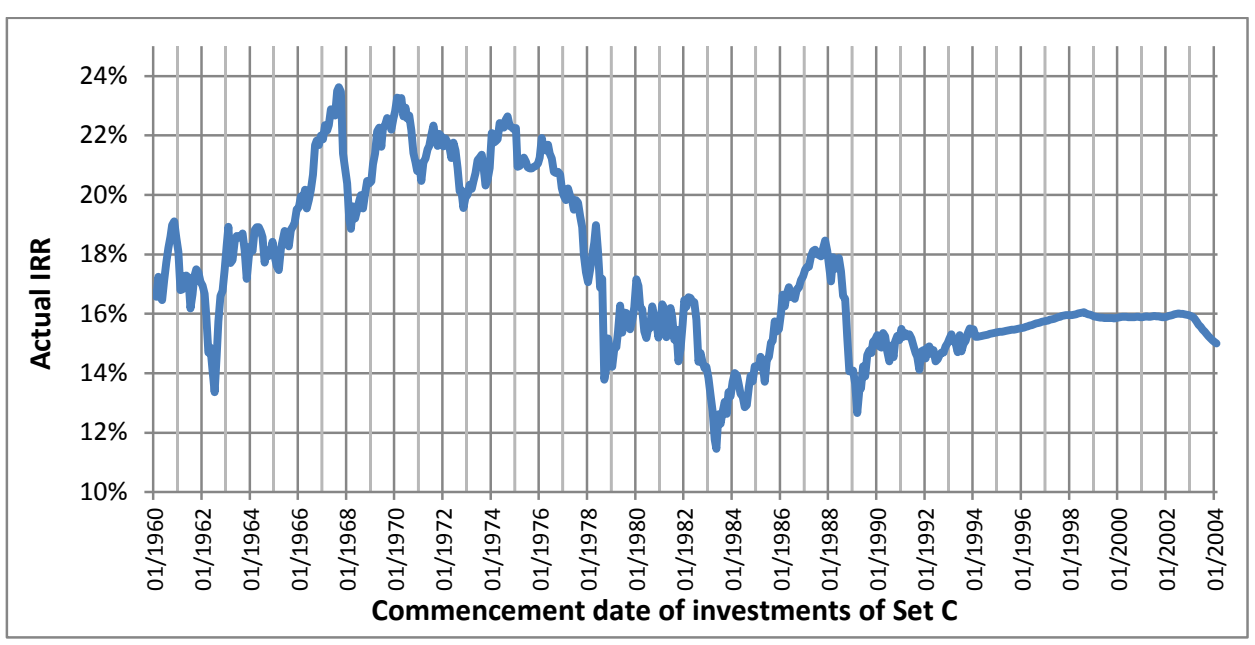

\section{FIGURE 5: IRRs generated by the monthly investments of Set C}

Source: Authors' deductions

The volatility of this set of IRR values is presented in TABLE 8.

\section{TABLE 8: Volatility of the IRRs of the investments of Set C}

\begin{tabular}{ll}
\hline Average IRR: & $17.32 \%$ p.a. \\
Standard deviation: & $2.73 \%$ \\
Kurtosis: & -0.79 \\
Skewness: & 0.56 \\
IRR< $11.07 \%$ p.a. (target return) & 0 \\
\hline
\end{tabular}

Source: Authors' deductions

TABLE 8 indicates that the STD of the IRRs of the investments in Set C is $2.73 \%$. This is significantly lower than the STD of the Alsi at $20.96 \%$, calculated previously from TABLE 3 .

The downside IRR probabilities of investments in Set $C$ in the Alsi are indicated in TABLE 9.

TABLE 9: Probabilities of downside IRR of the investments in Set C

\begin{tabular}{ll}
\hline Probability estimate & IRR to be less than figure below: \\
\hline $2.5 \%$ & $11.96 \%$ \\
$0 \%$ & $11.07 \%$ (the target return) \\
\hline
\end{tabular}

Source: Authors' deductions

TABLE 9 indicates an estimated probability of $2.5 \%$ that the IRR will be less than $11.96 \%$. There is no indication that the IRR will be lower than the target return of $11.07 \%$. Based on the results of the investments in Set C, the risk of investing in the Alsi is acceptable for a retirement portfolio. 
It can again be concluded that the analysis of short-term volatility of the Alsi does not give an accurate indication of the risk of investing in the Alsi over a long term in a retirement portfolio.

\subsubsection{Simulated living annuities based on the Topi}

Set $D$ represents simulated investments based on living annuities made in the Topi after retirement. The IRR values calculated for Set D are presented in FIGURE 6.

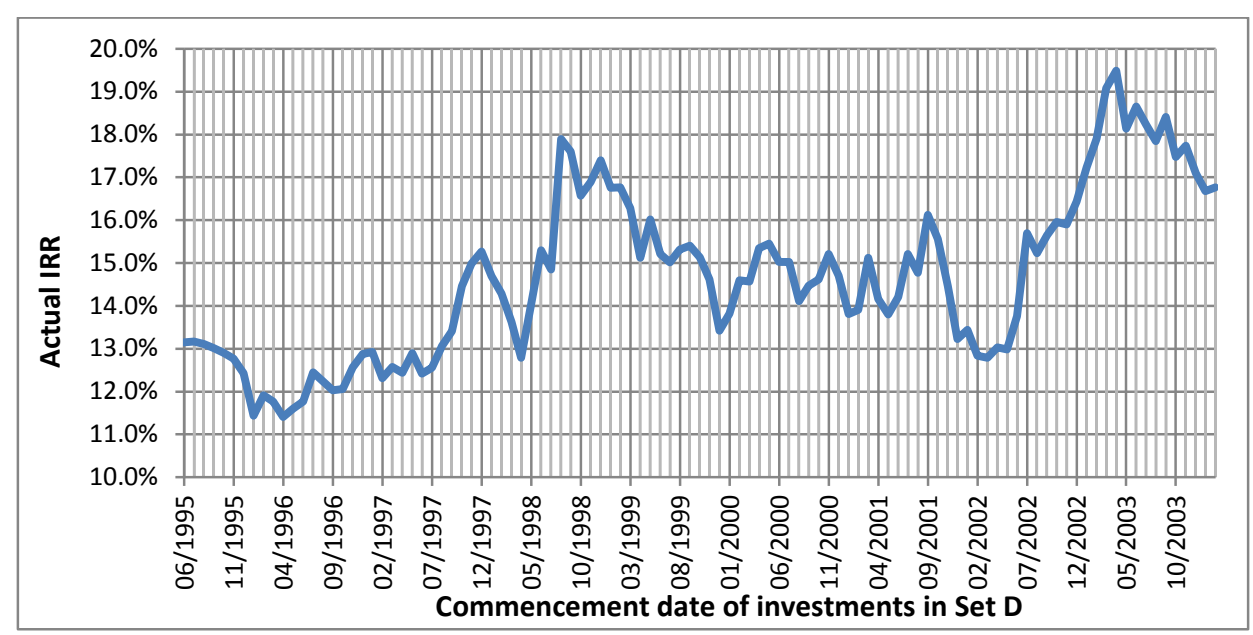

\section{FIGURE 6: $\quad$ IRRs of Set D simulated living annuities invested in the Topi}

Source: Authors' deductions

FIGURE 6 indicates a range of IRRs between $11.4 \%$ and $19.5 \%$ for Set $D$ investments in the Topi. The minimum IRR is in excess of the target return of $11.07 \%$.

The volatility for this set of IRR values is presented in TABLE 10 .

TABLE 10: Volatility of the IRRs of the investments of Set D

\begin{tabular}{ll}
\hline Average IRR: & $14.67 \%$ p.a. \\
Standard deviation: & $1.94 \%$ \\
Kurtosis: & -0.59 \\
Skewness: & 0.41 \\
IRR< $11.07 \%$ p.a. (target return) & 0 \\
\hline
\end{tabular}

Source: Authors' deductions

TABLE 10 indicates that the STD of the IRRs of the investments in Set D is $1.94 \%$. This is significantly lower than the STD of the Topi at $20.40 \%$, calculated previously from TABLE 3 ).

The downside IRR probabilities of investments in Set $D$ in the Topi are indicated in TABLE 11 . 
TABLE 11: Probabilities of downside IRR of the investments in Set D

\begin{tabular}{ll}
\hline Probability estimate & IRR to be less than percentage below: \\
\hline $2.5 \%$ & $10.86 \%$ p.a. \\
$0 \%$ & $11.07 \%$ p.a. (target return) \\
\hline
\end{tabular}

Source: Authors' deductions

TABLE 11 indicates an estimated probability of $2.5 \%$ of a return less than $10.86 \%$ and a $0 \%$ probability of a return less than the target return. This anomaly relates to the different methodologies used to estimate probabilities. The $2.5 \%$ probability of a return of less than $10.86 \%$ per annum is based on the confidence interval of $95 \%$ of 1.96 STDs. The distribution is not normal, but positively skewed and with a negative excess kurtosis. This affects the accuracy of the estimate. The probability estimate of zero that the IRR will be less than $11.07 \%$ is based on an actual count of returns less than $11.07 \%$ in the sample. This provides a more accurate probability estimate than the one based on the confidence interval of the distribution.

Based on these results, the risk of investing in the Topi is acceptable for inclusion in a retirement portfolio. These results further confirm the previous conclusion that analysis of short-term volatility does not give an accurate indication of the risk of long-term equity investment in a retirement portfolio.

\subsubsection{Simulated living annuities based on the Alsi}

The living annuity investments in the Alsi are referred to as $\operatorname{Set} \varepsilon$. The IRRs calculated for $\operatorname{Set} \varepsilon$ are presented in FIGURE 7.

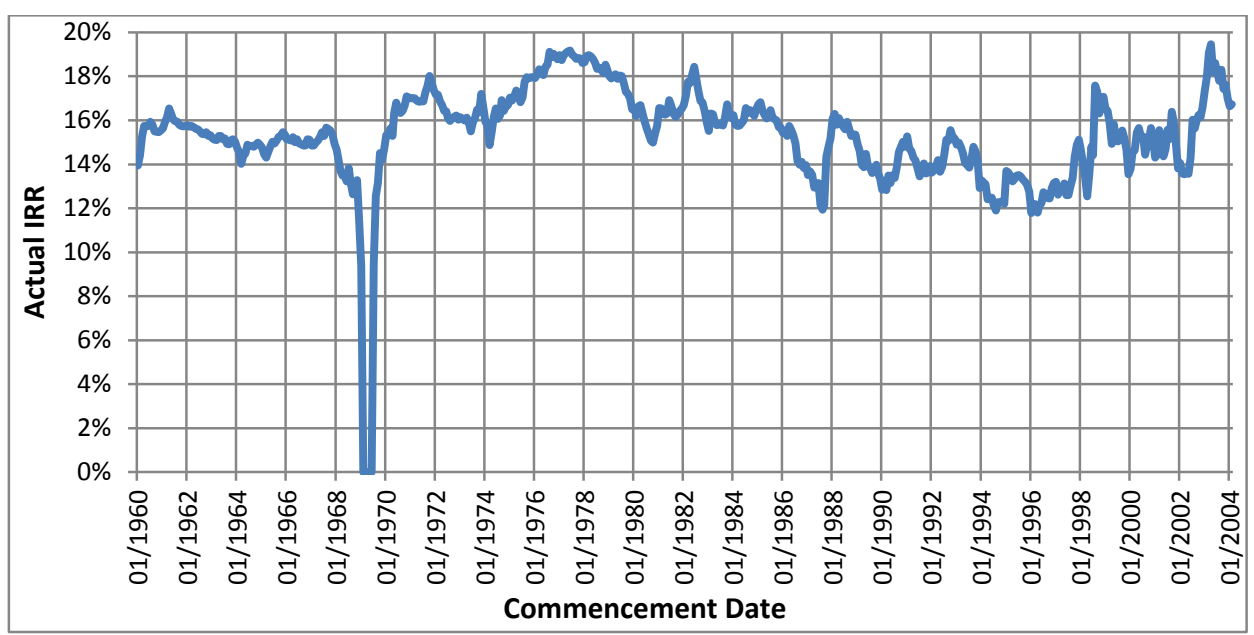

\section{FIGURE 7: IRRs of Set $\varepsilon$ of simulated living annuities investing in the Alsi}

Source: Authors' deductions

FIGURE 7 indicates a range of IRRs between $9.4 \%$ and $19.4 \%$. This range excludes five data points at the beginning of 1969, where the investments were depleted before the planned duration of 35 years. 
TABLE 12 indicates the volatility of the IRRs of Set $\varepsilon$ investments in the Alsi, excluding the five data points where funds were depleted.

TABLE 12: Volatility of the IRRs of the investments of Set $\varepsilon$

\begin{tabular}{ll}
\hline Average IRR: & $15.40 \%$ p.a. \\
\hline Standard deviation: & $1.80 \%$ \\
Kurtosis: & 0.59 \\
Skewness: & -0.31 \\
IRR $<11.07 \%$ p.a. (target return) & 7 \\
\hline
\end{tabular}

Source: Authors' deductions

TABLE 12 indicates that the STD of the IRRs of the investments in Set $\varepsilon$ is $1.80 \%$. This is significantly lower than the STD of the Alsi at $20.96 \%$ calculated previously from TABLE 3 ).

The downside probabilities of investments of Set $\varepsilon$ are indicated in TABLE 13.

TABLE 13: Probabilities of downside IRRs of investments in Set $\varepsilon$

\begin{tabular}{ll}
\hline Probability estimate & IRR to be less than percentage below: \\
\hline $2.5 \%$ & $11.87 \%$ p.a. \\
$1.3 \%$ & $11.07 \%$ p.a. (target return) \\
\hline
\end{tabular}

Source: Authors' deductions

TABLE 13 indicates an estimated probability of $2.5 \%$ that the IRR will be less than $11.87 \%$. The estimated probability that the IRR will be less than the target return is $1.3 \%$. Based on the results of the investments in Set $\varepsilon$, the risk of investing in the Alsi is acceptable for a retirement portfolio.

The results of the IRR values of this fifth set of investments again confirm previous conclusions that analysis of short-term volatility does not give an accurate indication of the risk of long-term equity investment in a retirement portfolio.

The IRR values of a total of 1797 investments were investigated. Only seven of these investments realised IRR values less than the target return. This provides conclusive evidence that the risk of investment in equity portfolios in the long term is low.

\section{SUMMARY AND CONCLUSION}

A common assumption in the construction of a retirement portfolio is that investors are willing to tolerate only a certain amount of risk. This is problematic, since the risk in equity investments is in many cases overstated and leads to the underutilisation of equity in retirement portfolios. To establish the risk of equity, this study analysed the riskiness of investments in the Topi and Alsi.

A target return was determined to evaluate the risk of not realising the required return of a retirement portfolio. The target return was established at $11.07 \%$ per annum. 
Investment risk was measured as the probability of not realising the target return. It was concluded that the probability of not reaching the target return should not be more than $2.5 \%$ for the risk to be acceptable for a retirement portfolio.

The conventional definition of the risk of an investment is directly related to the volatility of investment returns. The volatility of the Topi and the Alsi measured by STD indicated STDs of $20.40 \%$ and $20.96 \%$. The estimated probabilities of not achieving the target return of $11.07 \%$ were $45.8 \%$ and $43.8 \%$. Based on this risk profile, the risk of investments in the Topi and Alsi not reaching the target return exceeds the minimum required probability of $2.5 \%$.

To confirm the risk profile, five sets of actual investments in the Topi and Alsi were simulated. The IRR of each investment was determined and compared with the target return. The volatility of investments of Sets A to $\varepsilon$ measured by the STD ranged between $0.22 \%$ and $2.73 \%$. The estimated probability of not reaching the target return of $11.07 \%$ ranged between zero and $1.3 \%$. This revealed that the risk of each of the five simulated sets of investments was acceptable for a retirement portfolio.

It was concluded that risk analysis should be based on the IRR of a long-term investment rather than short-term fluctuations of returns. Volatility measured by the standard deviation of returns does not provide an accurate measure of risk in equity investments in a retirement portfolio.

This study indicates that an alternative way of gauging equity risk is by measuring the probability that the IRR of investments over the long term is less than a target return. It is recommended that this methodology be applied in the construction of retirement portfolios.

The perception that the riskiness of investments in retirement portfolios should be linked to the volatility of the returns of an investment, and not to the volatility of the IRR of a long-term investment, has resulted in retirement portfolios based on an incorrect perception of risk. The equity content is reduced in favour of fixed interest securities with the effect that long-term growth is sacrificed. It is not a conclusion of this study that increasing the equity content to $100 \%$ will solve current retirement problems. The results indicate that retirement portfolios with a high equity content do not increase the risk in a retirement portfolio beyond acceptable levels. Higher equity content will provide better returns, which could make a meaningful contribution in solving some of the current problems in the retirement industry.

It is suggested that the following could be the subject for further study:

- Investigation of portfolios that combine equity and bonds, with different combinations of equity and bonds;

- The desirability of younger retirement fund members to invest in a $100 \%$ equity portfolio;

- Diversifying into offshore equities;

- The effectiveness of Regulation 28 of the Pension Funds Act to reduce risk for retirement fund members. 


\section{LIST OF REFERENCES}

Anon. (2014). INET BFA. Available: http://www.inetbfa.com. (Accessed 28 April 2014).

Anon, n.d. Life Annuity. Available: http://en.wikipedia.org/wiki/Life_annuity. (Accessed 6 August 2014).

Botha, M., Rossini, L., Geach, W., Goodall, B., Du Preez, L. \& Rabenowitz, P. (2014). The South African Financial Planning Handbook 2014. Durban: LexisNexis.

Brown, K.C. \& Reilly, F.K. (2009). Analysis of Investments and Management of Portfolios, $9^{\text {th }}$ edition. Mason: Thomson South-Western.

Campbell, J.Y. \& Shiller, R.J. (1998). Valuation Ratios and the Long-Run Stock Market Outlook. The Journal of Portfolio Management, 24(2), pp. 11-26.

Bryman, A. \& Bell, દ. (2003). Business Research Methods. New York: Oxford University Press.

De Swardt, L. (2001). Ontledings van beleggingsportefeuljes in selfgeadministreerde fondse in Suid Afrika. Masters dissertation. Pretoria: University of Pretoria. Department of Financial Management.

De Villiers-Strijdom, J. (2013). Comparing Annuity Options at Retirement. Masters dissertation.

Stellenbosch: Stellenbosch University. Available: http://scholar.sun.ac.za.

Dimson, E., Marsh, P., Staunton, M. \& Mauboussin, M.J. (2014). Credit Suisse Global Investment Returns Yearbook 2014. Zurich: Credit Suisse AG Research Institute. Available: https://publications.creditsuisse.com/tasks/render/file/?filelD $=\backslash 0 \varepsilon 0 A 3525-\varepsilon A 60-2750$ 71CE20B5D14A7818. (Accessed l May 2014).

Durban Pension Fund (n.d.). Investment Policy and Strategy Document.

Hickman, K., Hunter, H., Byrd, J., Beck, J. \& Terpening, W. (2001). Life Cycle Investing, Holding Periods and Risk. Journal of Portfolio Management, pp. 101-111.

Jordan, B.D. \& Miller, T.W.J. (2008). Fundamentals of Investments Valuation and Management, $4^{\text {th }}$ edition. New York: McGraw-Hill Irwin.

Life Offices Association of South Africa (LOA) (2008). Code on Living Annuities. Circular No: 82/2008. Available: http://www.docstoc.com/docs/18565164/LOA-CIRCULAR-22nd-FLOOR-ABSA-CENTRE-2RIEBEEK-STREET-P-0-BOX-5023. (Accessed 24 November 2013).

Lind, D.A., Marchal, W.G., Wathen, S.A. (2005). Statistical Techniques in Business and Economics, $12^{\text {th }}$ edition. New York: McGraw-Hill Irwin.

Malkiel, B. (2007). A Random Walk Down Wall Street, $9^{\text {th }}$ edition London: W.W. Norton \& Company.

Markowitz, H.M. (1952). Portfolio Selection. Journal of Finance, 7(1), pp. 77-91.

Markowitz, H.M. (1959). Portfolio Selection Efficient Diversification of Investments. New York: John Wiley \& Sons, Inc.

Nawrocki, D. (1999). A Brief History of Downside Risk Measures. Financial Analysts Journal, 8(3), pp. 9-25.

Rayhorn, C. \& Janson, K. (2011). Long-Run Returns for Retirement Portfolios: New Evidence. Denver, Academy of Financial Services. Available:

http://www.academyfinancial.org/11Conference/11Proceedings/(D5)\%20Rayhorn,\%20Janson.pdf. (Accessed 1 July 2013). 
Reichenstein, W. (1986). When Stock is Less Risky than Treasury Bills. Financial Analysts Journal, 42(6), pp. 71-75.

Reilly, F.K. \& Brown, K. (2006). Investment Analysis and Portfolio Management, $8^{\text {th }}$ edition. Mason: Thomson South-Western.

Rollinger, T.N. \& Hoffman, S.T. (2013). The Sortino Ratio: A Better Measure of Risk. Futures Magazine, 0102 Available: http://www.sunrisecapital.com/wpcontent/uploads/2014/06/Futures_Mag_Sortino_0213.pdf. (Accessed 1 September 2013)

Roy, A.D. (1952). Safety First and the Holding of Assets. Econometrica, 20(3), pp. 431-449.

Republic of South Africa (RSA) (1956). Pensions Fund Act, No 24 of 1956. Pretoria: Government Printer.

Spierdijk, L. \& Bikker, J. (2012). Mean Reversion in Stock Prices: Implications for Long-Term Investors. De Nederlandsche Bank Working Paper No. 343, Amsterdam.

Strydom, P. (2007). Saving Behaviour by South African Households, First National Bank Economic Services. Available: https://www.fnb.co.za/economics/econhtml/docs/SavingHouseholds.pdf. (Accessed 10 February 2013).

The South African Reserve Bank (2009). The Inflation Target. Available: https://www.resbank.co.za/MonetaryPolicy/DecisionMaking/Pages/InflationMeasures.aspx. (Accessed 10 August 2014).

University of Johannesburg Pension Fund. (2008). Individual Investment Options. 